Western University

Scholarship@Western

Earth Sciences Publications

Earth Sciences Department

$1-2-2016$

\title{
Limiting the impact of destructive analytical techniques through sequential microspatial sampling of the enamel from single teeth
}

Alexis E. Dolphin

The University of Western Ontario, adolphin@uwo.ca

Mathew A. Teeter

The University of Wesstern Ontario, mteeter2@uwo.ca

Christine D. White

The University of Western Ontario, white2@uwo.ca

Fred J. Longstaffe

The University of Western Ontario, flongsta@uwo.ca

Follow this and additional works at: https://ir.lib.uwo.ca/earthpub

Part of the Biological and Physical Anthropology Commons, and the Earth Sciences Commons

Citation of this paper:

Dolphin, Alexis E.; Teeter, Mathew A.; White, Christine D.; and Longstaffe, Fred J., "Limiting the impact of destructive analytical techniques through sequential microspatial sampling of the enamel from single teeth" (2016). Earth Sciences Publications. 5.

https://ir.lib.uwo.ca/earthpub/5 
Title: Limiting the impact of destructive analytical techniques through sequential microspatial sampling of the enamel from single teeth

Authors: $\quad$ Alexis E. Dolphin ${ }^{1}$ Mathew A. Teeter ${ }^{1}$ Christine D. White ${ }^{1}$ Fred J. Longstaffe ${ }^{2}$

${ }^{1}$ Department of Anthropology, The University of Western Ontario, London, Ontario, Canada, N6A 5B7

${ }^{2}$ Department of Earth Sciences, The University of Western Ontario, London, Ontario, Canada, N6A 5B7

Abbreviated title: Applying multiple microspatial analytical techniques to tooth enamel

Keywords: teeth, microspatial sampling, histology, LA-ICP-MS, micromill, preservation ethic

Corresponding Author: Alexis E. Dolphin

Department of Anthropology

Western University

1151 Richmond Street

London, Ontario, Canada N6A 5C2

Tel: 226-268-7380

Fax: 519-661-2157

Email: adolphin@uwo.ca

Grant sponsorship: $\quad$ Social Sciences Humanities Research Council (SSHRC) Research Development Initiative grant \# 820-2007-1064 


\begin{abstract}
A fundamental research concern within contemporary bioarchaeology is the sensitive balance between the preservation of human remains and the use of destructive techniques to collect information. Here we describe one example of how multiple microspatial destructive/semidestructive techniques may be carried out in sequence using only the enamel of a single tooth. With careful planning of both sample preparation strategies and sequencing of sampling methods, it is possible to produce multiple datasets, and yet to retain material for future analyses. In this case, enamel from the teeth of 27 individuals who lived during the early medieval period (AD 1170-1198) in Bergen, Norway, were subjected to histological, trace element (LA-ICPMS), diagenetic (FTIR), and isotopic analyses $\left(\delta^{18} \mathrm{O}\right.$ and $\delta^{13} \mathrm{C}$, via micromill/multiprep/IRMS).
\end{abstract}




\section{Introduction}

A fundamental research concern within contemporary bioarchaeology is the sensitive balance between the preservation of human skeletal and dental remains and the use of destructive analyses to collect data. Archaeological human remains not only provide unique opportunities to gain understandings of an individual and/or group's past, but they also hold significant meaning and power for the descendant communities to which they are tied. And so, research involving human remains merits the development of sampling methodologies that will best satisfy the preservation ethic, even as the potential for data collection and interpretive possibilities are maximized. The sampling strategy and sequence of microspatial sampling presented here represents but one way by which we may work toward such an achievement.

In recent years the development of various microspatial sampling techniques has made it possible to minimize destruction of irreplaceable materials, and also to access discrete regions of interest within those materials. This has especially been the case for studies involving the microstructure and chemical composition of dental tissues (enamel, dentine, cementum) although there has also been growing exploration of the meaning of microspatial chemical variations in bone (Scharlotta et al. 2013). A significant effort to develop microspatial sampling techniques for teeth (human and non-human) comes from within fields such as anthropology and archaeology (Dolphin et al. 2005; Cucina et al. 2007; Copeland et al. 2008; Humphrey et al. 2008; Richards et al. 2008; Aubert et al. 2012; Metcalfe and Longstaffe 2012; Farell et al. 2013; Pfeiffer et al. 2013), and health and environmental sciences (Lochner et al. 1999; Arora and Austin 2013; Becker 2013), among others. Such research stems from a desire to capture information that is only accessible through assessment of the incremental formation (at a known rate) of dental tissues, and examination of their incorporation of elements from the environment 
during development. The ability to understand temporal variation in the chemical signatures preserved in teeth relies on the availability of data derived from histological analyses of dental microstructures such as accentuated striae of Retzius (Wilson bands) and cross-striations. It also relies on a careful consideration of the impact that variability in mineralization rates will have on the ability to interpret such data (Montgomery et al. 2010; Scharlotta and Weber 2014).

Histological analysis of dental microstructures in archaeological teeth can be problematic as it requires the permanent embedding of samples in a resin block, thus making their removal for bulk dissolution techniques later on difficult to impossible. Similarly problematic are the traditional bulk dissolution methods themselves, which homogenize the variable chemical composition data recorded in each tooth (Copeland et al. 2008). In terms of stable isotope and trace element research, some researchers have moved away from the traditional bulk sampling approaches that see entire teeth and/or tooth crowns destroyed, and toward other techniques which are less destructive. Some of these techniques may involve mechanical grinding and drilling of small areas within a sample (Hufthammer et al. 2010), or acid dissolution of successive layers of tissue. While chemical analyses such as electron probe x-ray microanalysis (EPXMA), secondary ion mass spectrometry (SIMS), proton-induced x-ray emission spectroscopy (PIXE), or synchrotron x-ray fluorescence (sXRF), have all been applied to the analysis of the chemical composition of dental tissues, laser ablation-inductively coupled plasma - mass spectrometry (LA- ICP-MS) is the most commonly utilized technique for conducting microspatial analyses of dental hard tissues (Lochner et al. 1999; Goodman et al. 2003; Kang et al. 2004; Grün et al. 2008; Humphrey et al. 2008; Dolphin and Goodman 2009; Hare et al. 2011; Vašinová Galiová et al. 2012; Austin et al 2013; Farell et al. 2013) . Laser ablation-ICP-MS allows for rapid multi-elemental analysis, with samples extracted from ablated spots with 
diameters as small as $5 \mu \mathrm{m}$. Together with its high sensitivity and low detection limits, LA-ICPMS makes possible the mapping of chemical variation with minimal sample destruction.

While histological and microspatial chemical techniques take advantage of the incremental growth structure of teeth, and their variable responses to physiological stress, diet/nutrition, or exposure to environmental pollutants, they are still inescapably semi-destructive. In keeping with the preservation ethic of bioarchaeology, then, the work presented here offers an example of how multiple microspatial techniques may be combined in sequence so as to maximize the kinds of data that may be retrieved from a single sample - in fact, from a single tooth tissue. These data include estimates of the frequency and timing of childhood stress episodes via histological analyses, pollutant exposure data gathered using trace element analyses (LA-ICP-MS), assessment of tissue preservation using Fourier transform infrared spectroscopy (FTIR), and isotopic analyses of $\delta^{18} \mathrm{O}$ and $\delta^{13} \mathrm{C}$ contributed data regarding origins/migration and palaeodiet, respectively.

\section{Materials and Methods}

One permanent tooth from each of 27 individuals excavated from St. Mary's (Mariakirken) churchyard at Bryggen, representing burials occurring between 1170 and $1198 \mathrm{AD}$ in Bergen, Norway, was subjected to multiple, semi-destructive, microspatial analytical techniques. Nitrogen and oxygen isotope ratios derived from bone samples were also assessed, but are not discussed here as they used more traditional dissolution, rather than microspatial, methods). The human skeletal and dental remains from Bryggen are fragmentary and incomplete for most individuals excavated, and also exhibit considerable dental wear. Thus, teeth were chosen for this study if macroscopic evaluation indicated that that they were likely well-preserved, with at least 
one intact cusp (no wear, cracks, caries, etc.) and no visible signs of alteration. The tooth sample ultimately included a combination of intact permanent canines $(\mathrm{N}=6)$, premolars $(\mathrm{N}=3)$, first molars $(\mathrm{N}=9)$, second molars $(\mathrm{N}=3)$ or third molars $(\mathrm{N}=6)$. A schematic showing sectioning and sampling regions of the teeth is provided in Figure 1. Figure 1. Schematic illustrating the sequence of sample preparation and microsampling procedures. $\mathrm{X}=$ thin section for histological analysis; A = longitudinal thick section for LA-ICP-MS; B = longitudinal thick section for micromilling. Laser ablation spots are represented by the square points located in the tooth enamel shown for section A. The white speckled trapezoidal boxes located within the tooth enamel of thin section B were micromilled first for the purposes of conducting isotope analyses. The black speckled trapezoidal box also located in section B indicates the removal of additional enamel for digenetic testing.

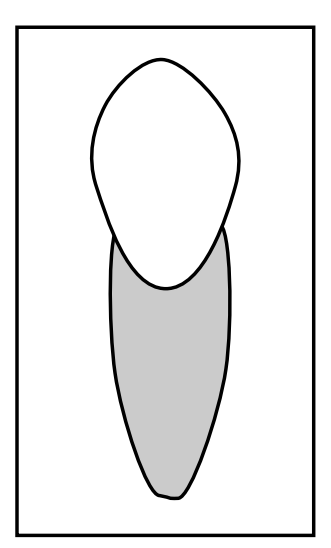

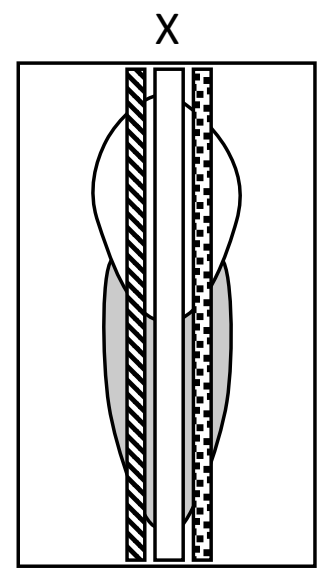

A B

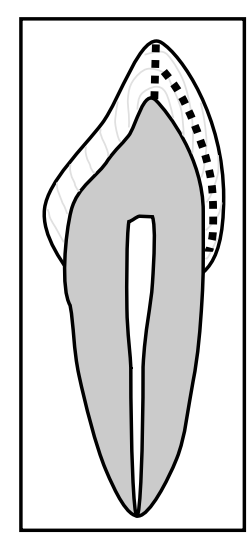

A

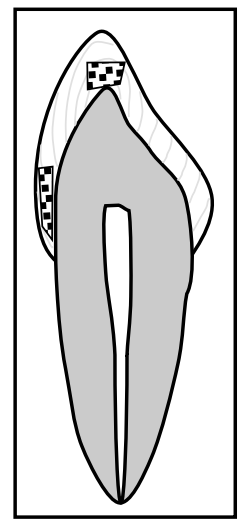

B

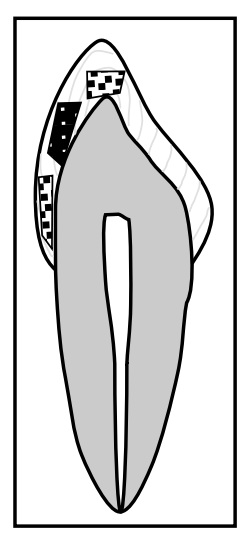

B

In the interests of focusing on the sequence of sampling techniques, and the preservation of sampled material, and because only standard microspatial methods were applied and have been 
cited in all cases, details of the operating conditions of the various instruments use, and of subsequent data analysis, are not addressed here.

\subsection{Step 1: Histology}

Once embedded in a resin block, longitudinal thin sections $(\sim 250 \mu \mathrm{m})$ were cut from the center of the best preserved cusp of each tooth using a Buehler Isomet 1000 slow speed saw. The remaining portions of each embedded tooth were retained for microspatial trace element and isotope analyses. Each thin-section was double-polished using a series of aluminum oxide slurries.

Sections were examined and photographed at 40x magnification under polarized light and images were knit together using the photomontage feature in Adobe Photoshop CS. To be counted as accentuated striae of Retzius, bands of dense enamel had to be visible from the enamel surface to the dentine-enamel junction (see Rose and Goodman 1990; Fitzgerald and Saunders 2005). The frequency and timing of periods of physiological disruption were documented for each individual in the sample.

\subsection{Step 2: Laser ablation - inductively coupled plasma - mass spectrometry (LA- ICP- MS)}

From one of the remaining tooth halves, a cut was made parallel to the tooth surface that was exposed when the thin section was taken. This second cut produced a longitudinal thick section $(\sim 250 \mu \mathrm{m})$, referred to here as "Block A". A Thermo Fisher Scientific Element 2 ICPMS and New Wave UP-213 laser was used to assess the presence of the following elements in

the enamel of each tooth: ${ }^{23} \mathrm{Na},{ }^{24} \mathrm{Mg},{ }^{25} \mathrm{Mg},{ }^{31} \mathrm{P},{ }^{43} \mathrm{Ca},{ }^{55} \mathrm{Mn},{ }^{65} \mathrm{Cu},{ }^{66} \mathrm{Zn},{ }^{68} \mathrm{Zn},{ }^{85} \mathrm{Rb},{ }^{88} \mathrm{Sr},{ }^{119} \mathrm{Sn}$, 


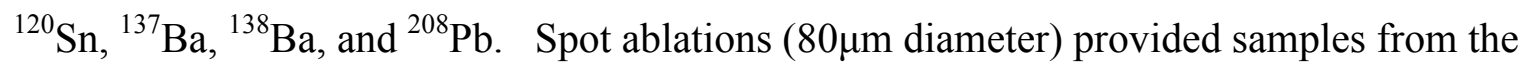
earliest to the latest layers of enamel. Thus, samples (of 15 to 22 spots, depending on the size of the crown) were taken from enamel at the dentin-enamel junction (DEJ), moving up toward the surface of the cusp, and then down its side toward the root (Figure 2). Outer and/or worn enamel was not sampled as it has been shown to be consistently enriched in, or depleted of, a number of trace elements examined here (see Budd et al. 1998; Lee et al. 1999; Reitznerová 2000; Dolphin et al. 2005).

Figure 2. Photograph demonstrating the size, location and number of laser ablation spot samples taken from the enamel crown. Arrows indicate the location of a number of these spots; which run from the dentine-enamel junction at the tooth cusp to the surface of the cusp, and then down the side of the tooth enamel.

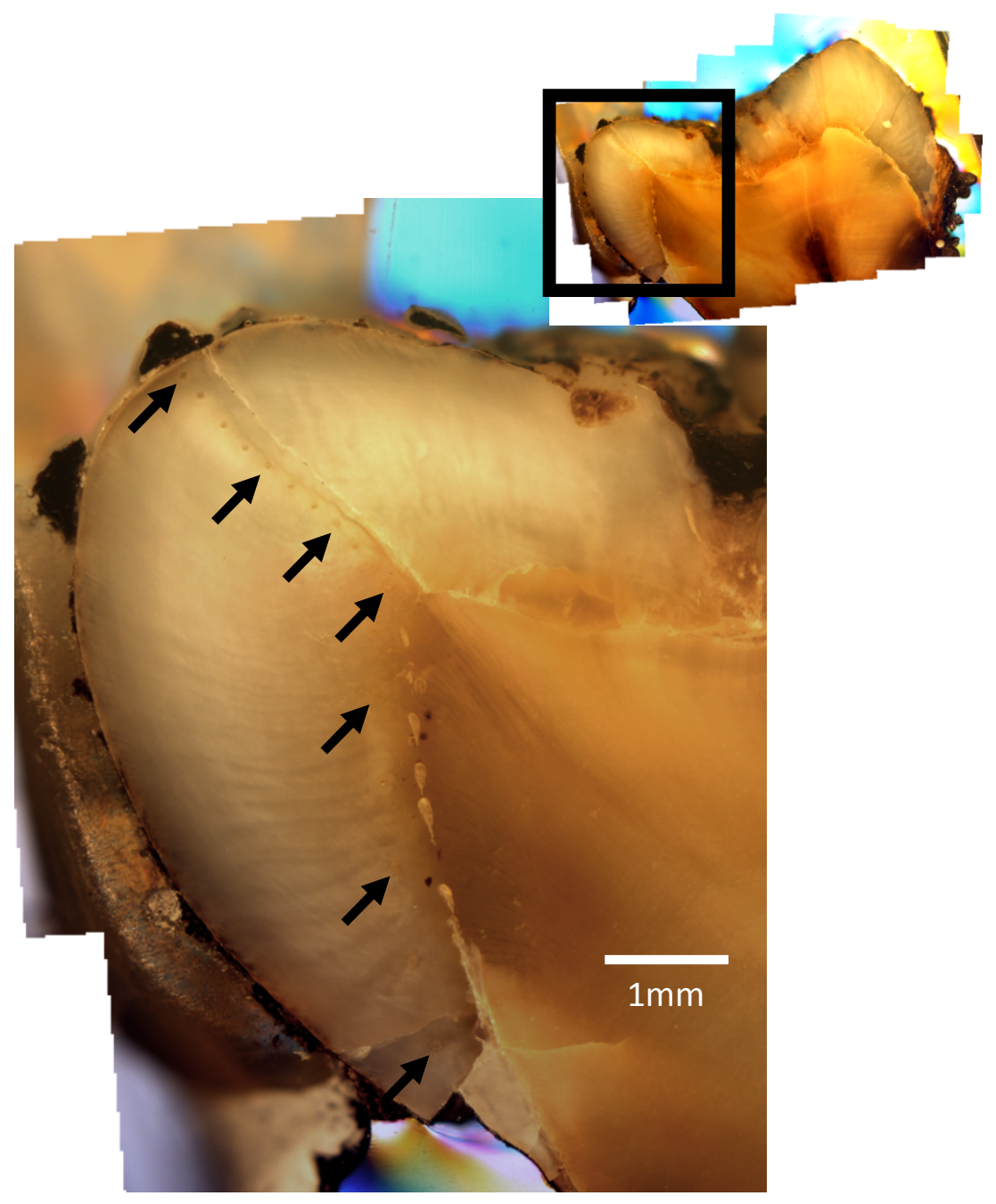


Using Glitter 4.0 software, a bone meal standard reference material (NIST 1486) was analyzed with a NIST612 glass standard serving as a calibrant, and $\mathrm{Ca}^{43}$ was used as an internal standard (Simonetti et al. 2008; Castro et al. 2010; Hare et al. 2011). The spot ablations removed such extremely small samples (difficult to see with the naked eye) from the tooth crown that "Block A" was retained for future analyses of the remaining dental tissues.

\subsection{Step 3: Micromill}

From the remaining one half of the embedded tooth, a second longitudinal thick section of 250 microns was cut ("Block B”) and prepared for the micromilling of enamel samples in order to conduct stable isotope analyses. For each individual, "Block B" was sampled using a Leica GZ6 Merchantek micromill - a device that can be used to drill out very small samples of hard materials with great precision. Two samples ( $2 \mathrm{mg}$ each) of enamel were taken from "Block B", per individual. The first sample represented an earlier period of growth and the second sample represented the latest period of growth recorded by the enamel. These samples were milled in order to explore life time mobility by comparing $\delta^{18} \mathrm{O}$ values within tissues (the mobility study included data from analyses of $\delta^{18} \mathrm{O}$ from the bones of each individual as well).

The sampling area was chosen by examining the histological sections produced with Step

1. Each of the two samples per tooth was reserved for isotopic analyses. Figure 3 provides an example of the regions of "Block B" that were micromilled for the purposes of stable isotope analyses and the assessment of alterations of the enamel in question. 
Figure 3. Photograph showing the location and size of micromilled sample areas. $\mathrm{A}=$ areas milled to produce samples for structural carbonate analyses of oxygen isotopes; $\mathrm{B}=$ area milled to produce a sample of tooth enamel for the purposes of diagenetic testing.

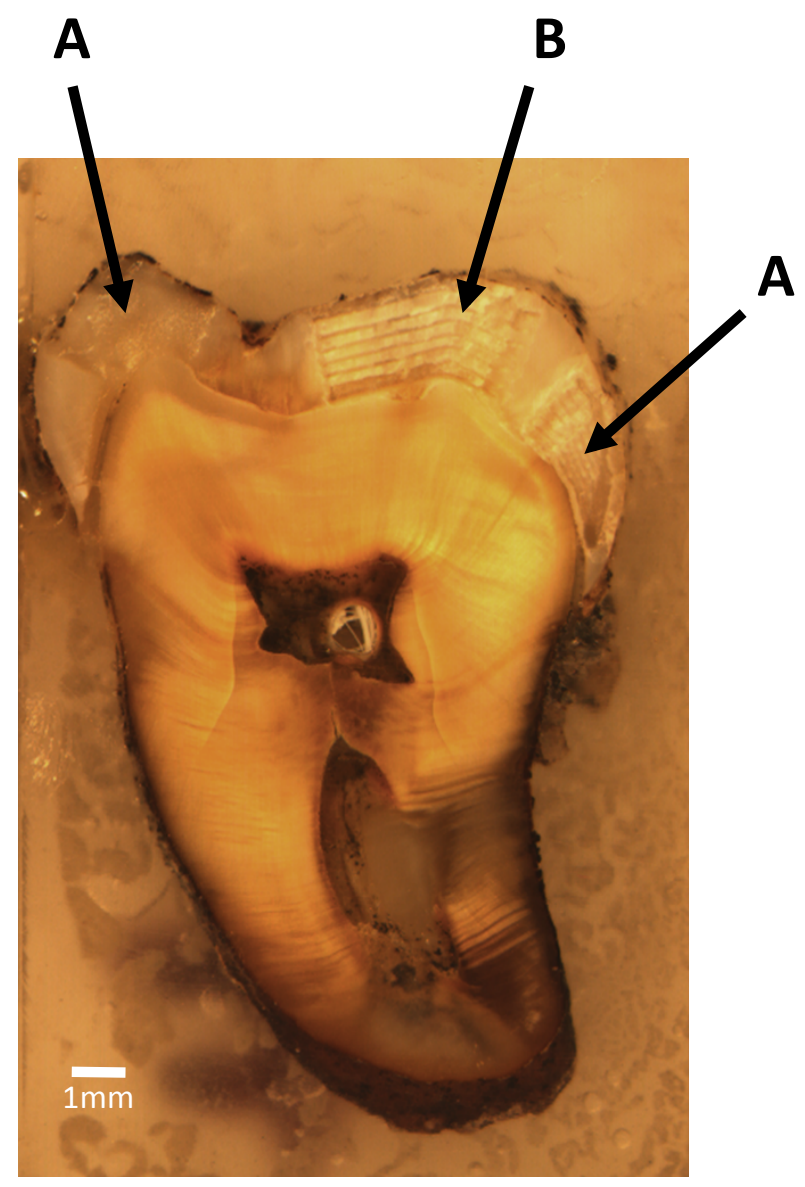

\subsection{Step 4: Fourier transform infrared spectroscopy (FTIR)}

The longitudinal thick sections $(>200 \mu \mathrm{m})$ used for the trace element analysis, and micromill sampling were also used to assess the state of preservation via Fourier transform infrared spectroscopy analysis (FTIR). FTIR analysis and crystallinity index (CI) determinations were conducted using a Bruker Vector 22 Spectrometer according to standard protocols developed in the Laboratory for Stable Isotope Science (LSIS) at The University of Western 
Ontario, London, Ontario, Canada. The results of these analyses allowed us to test for postmortem alteration prior to moving forward with investigating the stable isotopes.

\subsection{Step 5: Isotopic Analyses}

The powdered samples from both "early" and "late" forming enamel, as obtained through micromilling, were used to assess $\delta^{18} \mathrm{O}$ and $\delta^{13} \mathrm{C}$ signatures from the structural carbonate component of the tooth enamel (Sponheimer and Lee-Thorp 1999; Pasteris et al. 2008; Metcalfe et al. 2009). Although each sample was approximately $2 \mathrm{mg}$ in weight, $\sim 0.89 \mathrm{mg}$ subsamples (on average) were used for both the oxygen and carbon isotope analyses, with the remaining powdered enamel being used to analyze several duplicates in order to test for instrument accuracy. Structural carbonate isotope analysis was conducted using a Micromass MultiPrep carbonate device attached to a Micromass Optima dual-inlet IRMS. The remaining portion of "Block B" (some enamel and all dentine) was retained for the purposes of conducting future research regarding this sample of individuals.

\section{Results}

Both Figures 2 and 3 illustrate the sampling strategy employed, yet they also demonstrate the amount of each dental tissue remaining after material was removed by/for the various analytical techniques. There is a considerable retention of enamel material after LA-ICP-MS sampling, of "Block A" (Figure 2). For "Block B", micromilling removed most of the surface of the exposed enamel, but only to a depth of 65 microns, thus preserving some enamel for future analysis. For both blocks, dentine and cementum were left intact for the purposes of this project, but certainly it would be possible to extend trace element, isotopic, and other analyses to those 
tissues as well. Aside from the material remaining in these blocks, and the thin section produced for histological analysis, and as indicated by the schematic presented in Figure 1, lateral aspects of some teeth were also preserved. While the remaining lateral portions were quite large for molars, they are considerably smaller, and sometimes not always present for, samples taken from incisors and canines.

By carrying out a sequential sampling strategy it was possible to employ several analytical techniques and answer different, yet inter-related, questions regarding the meaning of physiological disruption during childhood, diet, pollution, mobility, and diagenesis (manuscripts in preparation). The production of standard histological thin sections of each tooth allowed for the determination of the number of accentuated striae of Retzius per tooth. Calculations regarding the periodicity of their occurrence resulted from the visualization of striae of Retzius and cross-striations (weekly and daily growth markers, respectively). Trace element analyses conducted via LA-ICP-MS showed that individuals' values for each element agree with the broad concentration categories summarized in the seminal work of Curzon and Cutress (1983:5). When examining the distribution of trace elements across growth/temporal bands, inter- and intra-individual variability was also identified and used to further comment upon the nutrition and exposure to pollutants of children in medieval Bergen. Crystallinity Index (CI) and C/P values produced via FTIR ruled out any significant influence of diagenesis upon the concentrations of trace elements or stable isotopes. The stable isotope analyses themselves demonstrated good sample reproducibility and agreement with accepted values. Further assessment of stable isotope variation within and between individuals is being considered in relation to the accentuated striae of Retzius and trace element results, as well as in relation to osteological and archaeological data. 


\section{All An4. Discussion and Conclusion}

This paper describes only one method for successfully employing a sample preparation strategy, and a suite of microspatial techniques, to build multiple complementary datasets from one dental tissue. Data collection may be maximized while ensuring the retention of sample material so that future analytical techniques can be used to add new information as technological capabilities and research goals evolve. A strength of this approach comes from the ability to use histological data to comment upon the timing of fluctuations in trace element and stable isotopic concentrations in tooth enamel. The timing of periods or waves of chemical variation can, in addition, be estimated relative to histological structures such as accentuated striae of Retzius, which may prove revealing regarding the nature of episodes of physiological stress experienced by children. Given that the sample used here was fragmentary and several surviving teeth were worn, it was necessary to be opportunistic in terms of including a variety of tooth types in the analyses. Although the teeth varied in terms of their size, or the amount of intact enamel available, they all provided enough material to conduct the analyses and conserve material for future work.

There are some limitations of this single tooth/tissue strategy that should be considered prior to application of this sequence, or another like it. The strategy presented here leaves no room for error. For example, if the single slide for histological analysis is lost during sample preparation another cannot be produced without sacrificing the blocks reserved for other aspects of the research project. Also, although a great deal of varied information was obtained, this was a time consuming process in terms of sample preparation and data collection (vs employing 
traditional dissolution techniques that destroy the entire sample). This significant time expenditure is countered by the fact that approximately only $6 \mathrm{mg}$ of tooth was lost to analysis. Some enamel and the entire dentine portion of the tooth remains, as well as the root structure and the cementum. The remaining tooth material can thus be used in future studies. For example, two years after the initial analyses discussed here, an unanticipated opportunity arose to produce fine elemental maps for one of the teeth using synchrotron X-ray Fluorescence (sXRF) on the VESPERS beamline at the Canadian Light Source synchrotron (Saskatoon, SK). This research added new knowledge regarding the relationship between trace element distributions and dental microstructures, and information about elements, such as Fe, which could not be captured via the original set of methods.

The goal of this paper has been to provide an example of a method for collecting multiple kinds of data from a single dental tissue in such a way that data are produced which are of equivalent quality as those derived from more traditional and more destructive sampling strategies. This is certainly not the only sequence or set of methodological techniques one might want to employ. Our hope is that the example presented here will serve to build awareness of some microspatial options available to researchers, and of their enhanced value when combined. With careful planning, and the application of microspatial sampling strategies, it is possible to maximize data acquisition while preventing the complete loss of irreplaceable sample material, which is becoming more and more necessary for anyone hoping to do research with human tissues (ancient or contemporary). The sequence of sampling and analysis presented here is but one example of how this might be done, and given that there are significant portions of each sample remaining, this project has demonstrated that, even with such rich data gathering, preservation of material for future research endeavors is entirely possible. 


\section{ACKNOWLEDGEMENTS}

We would like to gratefully acknowledge the access to samples provided byAnne Karin Hufthammer (Bergen Museum, Bergen, Norway), as well as the technical advice provided by Kim Law, Li Huang, Zoe Morris, Paul Szpak, and Meridith Masoner (The Laboratory for Stable Isotope Science at UWO (LSIS); and Jan Kosler and Siv Hjorth Dundas (Geobiosciences Laboratory at the University of Bergen). Dolphin would additionally like to acknowledge Ian Coulthard and the other fine people at the Canadian Light Source, for providing a new opportunity to further examine these samples. Appreciation is also extended to the Social Sciences and Humanities Research Council of Canada for its support of Dolphin's Research Development Initiative grant \#820-2007-1064. Funding for the stable isotope infrastructure was provided by the Canada Foundation for Innovation and the Ontario Research Fund (and its precursors). This is LSIS Contribution \# 311. 


\section{References}

Arora M, Austin C. 2013. Teeth as a biomarker of past chemical exposure. Curr Opin Pediatr 25(2):261-267.

Aubert M, Williams IS, Boljkovac K, Moffat I, Moncel M-H, Dufour E, Grün, R. 2012. In situ oxygen isotope micro-analysis of faunal material and human teeth using a SHRIMP II: a new tool for palaeo-ecology and archaeology. J Archaeol Sci 39(10):3184-3194.

Austin C, Smith TM, Bradman A, Hinde K, Joannes-Boyau R, Bishop D, Hare DJ, Doble P, Eskenazi B, Arora M. 2013. Barium distributions in teeth reveal early-life dietary transitions in primates. Nature 498:216-219.

Becker JS. 2013. Imaging of metals in biological tissue by laser ablation inductively coupled plasma mass spectrometry (LA-ICP-MS): state of the art and future developments. J Mass Spectrom 48(2):255-268.

Budd P, Montgomery J, Cox A, Krause P, Barreiro B, Thomas RG. 1998. The distribution of lead within ancient and modern human teeth: Implications for long-term and historical exposure monitoring. Sci Total Environ 220: 121-136.

Castro, W., Hoogewerff, J., Latkoczy, C., Almirall, J.R., 2010. Application of laser ablation (LA-ICP-SF-MS) for the elemental analysis of bone and teeth samples for discrimination purposes. Forensic Sci Int 195: 17-27.

Copeland SR, Sponheimer M, le Roux PJ, Grimes V, Lee-Thorp JA, de Ruiter DJ, Richards MP. 2008. Strontium isotope ratios $(87 \mathrm{Sr} / 86 \mathrm{Sr})$ of tooth enamel: a comparison of solution and laser ablation multicollector inductively coupled plasma mass spectrometry methods. Rapid Commun Mass Sp 22(20):3187-3194.

Cucina A, Dudgeon J, Neff H. 2007. Methodological strategy for the analysis of human dental enamel by LA- ICP-MS. J Archaeol Sci 34:1884-1888.

Curzon, M.E., Cutress, T.W., 1983. Trace elements and dental disease. J. Wright/Psg Inc.

Dolphin AE, Goodman AH. 2009. Maternal diets, nutritional status, and zinc in contemporary Mexican infants' teeth: implications for reconstructing paleodiets. Am J Phys Anthropol 140:399-409.

Dolphin AE, Goodman AH, Amarasiriwardena D. 2005. Variation in elemental intensities among teeth and between pre and postnatal regions of enamel. Am J Phys Anthropol 128:878888 . 
Farell J, Amarasiriwardena D, Goodman AH, and Arriaza B. 2013. Bioimaging of trace metals in ancient Chilean mummies and contemporary Egyptian teeth by laser ablationinductively coupled plasma-mass spectrometry (LA-ICP-MS). Microchem J 106:340346.

FitzGerald CM, Saunders SR. 2005. Test of histological methods of determining chronology of accentuated striae in deciduous teeth. Am J Phys Anthropol 127:277-290.

Goodman AH, Dolphin AE, Amarasiriwardena D, Klein R, Backstrand, JR, Reid JB Jr. 2003. Tooth rings: dental enamel as a chronological biomonitor of elemental absorption from pregnancy to adolescence. J Child Health 1:203-214.

Goodman AH, Rose JC. 1990. Assessment of systemic physiological perturbations from dental enamel hypoplasias and associated histological structures. Yearb Phys Anthropol 33:59-110.

Grün R, Aubert M, Joannes-Boyau R, Moncel M-H, 2008. High resolution analysis of uranium and thorium concentration as well as $\mathrm{U}$-series isotope distributions in a Neanderthal tooth from Payre (Ardèche, France) using laser ablation ICP-MS. Geochim et Cosmochim Ac 72: 52785290.

Hare D, Austin C, Doble P, Arora M, 2011. Elemental bio-imaging of trace elements in teeth using laser ablation-inductively coupled plasma-mass spectrometry. J Dent 39: 397-403.

Hufthammer AK, Høie H, Folkvord A, Geffen AJ, Anderssson C, Ninnemann US. 2010. Seasonality of human site occupation based on stable oxygen isotope ratios of cod otoliths. J Archaeol Sci 30:47-55.

Humphrey LT, Dean MC, Jeffries TE, Penn M. 2008. Unlocking evidence of early diet from tooth enamel. P Natl Acad Sci 105(19):6834-6839.

Kang D, Amarasiriwardena D, Goodman AH. 2004. Application of laser ablation-inductively coupled plasma-mass spectrometry (LA- ICP-MS) to investigate trace metal spatial distributions in human tooth enamel and dentine growth layers and pulp. Anal Bioanal Chem 378:1608-1615.

Lee, KM, Appleton, J, Cooke, M, Keenen, F, Sawicka-Kapusta, K. 1999. Use of laser ablation inductively coupled plasma mass spectrometry to provide element versus time profiles in teeth. Anal Chim Ac 395(1-2):179-185.

Lochner F, Appleton J, Keenan F, Cooke M. 1999. Multi-element profiling of human deciduous teeth by laser ablation-inductively coupled plasma-mass spectrometry. Anal Chim Acta 401:299-306.

Metcalfe JZ, Longstaffe FJ. 2012. Mammoth tooth enamel growth rates inferred from stable isotope analysis and histology. Quaternary Res 77(3): 424-432.

Metcalfe JZ, Longstaffe FJ, White CD, 2009. Method-dependent variations in stable 
isotope results for structural carbonate in bone bioapatite. J Archaeol Sci 36(1):110-121.

Montgomery J, Evans JA, Horstwood MSA, 2010. Evidence for long-term averaging of strontium in bovine enamel using TIMS and LA-MC-ICP-MS strontium isotope intra-molar profiles. Environ Archaeol 15(1): 32-42.

Pfeiffer, S., Williamson, R.F., Sealy, J.C., Smith, D.G., Snow, M.H. 2013. Stable dietary isotopes and mtDNA from Woodland period southern Ontario people: results from a tooth sampling protocol, J Archaeol Sci 40:334-345.

Reitznerová E, Amarasiriwardena D, Kopčáková M, Barnes RM, 2000. Determination of some trace elements in human tooth enamel. Fres J Anal Chem 367(8): 748-754.

Richards M, Harvati K, Grimes V, Smith C, Smith T, Hublin J-J, Karkanas P, Panagopoulou E, 2008. Strontium isotope evidence of Neanderthal mobility at the site of Lakonis, Greece using laser-ablation PIMMS. J Archaeol Sci 35(5): 1251-1256.

Scharlotta I, Goriunova OI, Weber A. 2013. Micro-sampling of human bones for mobility studies: diagenetic impacts and potentials for elemental and isotopic research. J Archaeol Sci 40(12): 4509-4527.

Scharlotta I, Weber A. 2014. Mobility of middle Holocene foragers in the Cis-Baikal region, Siberia: Individual life history approach, strontium ratios, rare earth and trace elements. Quatern Int 348: 37-65.

Shemesh A. 1990. Crystallinity and diagenesis of sedimentary apatites. Geochim Cosmochim Ac 54:2433-2438.

Simonetti A, Buzon MR, Creaser RA. 2008. In-situ elemental and Sr isotope investigation of human tooth enamel by laser ablation-(MC)-ICP-MS: Successes and Pitfalls. Archaeom 50(2):371-385.

Sponheimer M, Lee-Thorp JA, 1999. Oxygen isotopes in enamel carbonate and their ecological significance. J Archaeol Sci 26:723-728.

Pasteris JD, Wopenka B, Valsami-Jones E, 2008. Bone and tooth mineralization: why apatite? Elements 4:97-104.

Surovell TA, Stiner MC. 2001. Standardizing infra-red measures of bone mineral crystallinity: an experimental approach. J Archaeol Sci 28:633-642.

Vašinová Galiová M, Nývltová Fišáková M, Kynický J, Prokeš L, Neff H, Mason, AZ, Gadas P, Košler J, Kanický V. 2012. Elemental mapping in fossil tooth root section of Ursus arctos by laser ablation inductively coupled plasma mass spectrometry (LA-ICP-MS). Talanta 105:235243. 
Weiner S, Bar-Yosef, O. 1990. States of preservation of bones from prehistoric sites in the Near East: a survey. J Archaeol Sci 17:187-196.

Wright LE, Schwarcz HP. 1996. Infrared and isotopic evidence for diagenesis of bone apatite at Dos Pilas, Guatemala: paleodietary implications. J Archaeol Sci 23:933-944. 